\title{
CONSTRUÇÃO DE FORNOS SOLARES: UMA ATITUDE SUSTENTÁVEL PARA ERRADICAÇÃO DA POBREZA
}

\author{
Naiane Nunes Gonçalves', Rafaella Spilare Silva ${ }^{2}$, Renato Nunes de Andrade ${ }^{3}$, \\ Bruno Magela de Melo Siqueira4, Rafael Baioco Ruy ${ }^{5 *}$
}

Secretaria de Estado de Educação do Espírito Santo

Av. César Hilal, 1111 - Santa Lúcia - CEP: 29056-085 - Vitória - ES

\section{RESUMO}

O Projeto Forno Solar foi desenvolvido pelos bolsistas do Pibid de Química do Instituto Federal de Educação, IFES, junto ao professor supervisor, visando a conscientizar os alunos do Ensino Médio sobre recursos energéticos e responsabilidade social e ambiental de forma que possam, com base no respeito aos recursos naturais, empreender ações simples do cotidiano de maneira sustentável, utilizando energia solar, maior fonte de energia para a humanidade. A utilização do forno solar coopera com a preservação da natureza, uma vez que pode ser construído com materiais recicláveis e utiliza uma fonte de energia renovável. 0 forno solar pode ser utilizado em comunidades desprivilegiadas socialmente pelo seu baixo custo. Os testes realizados no verão foram satisfatórios e possibilitaram assar bolos, pizzas e pão de queijo, mas no inverno os resultados pretendidos não foram satisfatoriamente alcançados devido à pouca incidência de sol.

Palavras-chave: forno solar; energia solar; erradicação da pobreza.

\section{ABSTRACT}

The Solar Oven was a project developed by the fellows of Pibid of Chemistry, at Instituto Federal de Educação, IFES, in order to teach High School students about energy resources and our responsibility on environmental. The purpose was to show them we can, in simple everyday actions, such as preparing a food, act sustainably, by using solar energy, the largest source of energy for mankind. The use of solar oven cooperates with the preservation of nature, since it can be done with recycled materials and can reduce dependence on fossil fuels and forest resource. The solar ovens can be used for domestic purposes. This research showed the tests were satisfactory in the summer and allowed to bake cakes, pizza and cheese bread, but in winter time the desired results have not been satisfactorily achieved due to low incidence of the sun, having more time for heating the oven and incomplete cooking of foods.

Keywords: solar oven; solar energy, eradication of poverty.

\footnotetext{
${ }^{1}$ Estudante do curso de Licenciatura em Química / IFES - Campus Vila Velha / e-mail: naiane.nng@hotmail.com ${ }^{4}$ Estudante do curso de Licenciatura em Química / IFES - Campus Vila Velha / e-mail: rafaspilare@yahoo.com.br 2Estudante do curso de Licenciatura em Química / IFES - Campus Vila Velha / e-mail:

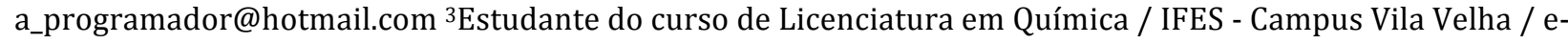
mail: brunosiq_es@hotmail.com 5*Mestre em Físico-Química (UFV) / SEDU - EEEM Prof. Renato Jose da Costa Pacheco / e-mail: rbaioco@yahoo.com.br
} 


\section{INTRODUÇÃO}

Este trabalho tem por objetivo relatar a experiência da construção de fornos solares na EEEM Prof. Renato José da Costa Pacheco, da cidade de Vitória-ES. A utilização do forno solar, por se tratar de um equipamento instigante, ecologicamente correto, relevante para economia de gás de cozinha, barato, fácil de construir, pode despertar nos alunos consciência quanto à importância da utilização de energias renováveis, pois o sol além de fonte de vida pode ser a resposta para a questão do abastecimento energético no futuro. Seria irracional não buscar meios de aproveitar esta fonte de energia limpa e gratuita. Os fornos solares foram construídos por alunos do $2^{o}$ ano do ensino médio, que se empenharam na confecção e entendimento de seu funcionamento, havendo grande interesse para testar sua eficácia.

\section{PROCEDIMENTOS METODOLÓGICOS}

O forno solar é um equipamento que concentra os raios solares em uma zona, permitindo aquecimento dos alimentos depositados em um recipiente isolado termicamente por meio do efeito estufa. Foi um dos projetos desenvolvidos pelos bolsistas do Pibid de Química do Instituto Federal do Espírito Santo, IFES, junto ao professor supervisor, visando conscientizar os alunos do Ensino Médio sobre a utilização de energias renováveis, responsabilidade social e ambiental de forma que possam aprender e transmitir os conhecimentos adquiridos com base no respeito aos recursos naturais. Foi feita uma abordagem sobre as vantagens do uso do forno solar, uma comparação entre o efeito estufa que ocorre no forno e o aquecimento global e sua utilidade, especialmente em comunidades carentes e locais remotos.

O seu uso ajuda na conservação de combustíveis convencionais como a lenha; a conservação da lenha das árvores ajuda na preservação dos ecossistemas, pois seu uso como fonte de energia esta associada a muitos problemas ambientais como empobrecimento dos solos, redução das chuvas, avanço do processo de desertificação e sua queima libera óxidos de carbono, que poluem o ar e intensificam o efeito estufa. 0 projeto envolveu grupos de alunos de diferentes turmas e resultou na confecção de cinco fornos solares, sendo dois na configuração de tronco de cone e três na configuração de caixa. Foram utilizados caixas de papelão, papel alumínio, placas de isopor, cola branca, papel cartão, barbante, tesoura sem ponta, conduíte corrugado e placas de vidro. 


\section{Confecção dos fornos em configuração de tronco de cone}

Devido à cidade de Vitória-ES estar localizada a $20^{\circ}$ sul de latitude, o forno em forma de tronco de cone foi projetado com um ângulo de abertura de 60ำ (30ํe em relação ao eixo y) para que se tenha uma maior incidência de raios solares em seu no interior. Para o forno em forma de tronco cone, foi desenhada sua planificação em papel cartão, usando a escala adequada, depois foram acertados os diâmetros de abertura superior e inferior do tronco e cortados os excessos das bordas. A parte interna do tronco de cone planificado foi revestida com papel alumínio e as abas foram coladas para fechá-lo. As bordas do tronco de cone foram reforçadas com conduíte corrugado para que ficassem mais firmes. Foram empregados cálculos de trigonometria e geometria espacial (Figura 1).

O forno propriamente dito, local onde ocorre o efeito estufa e cozimento dos alimentos, foi confeccionado em forma de caixa cilíndrica com papel cartão isolado termicamente com isopor. 0 interior da caixa foi revestido com papel alumínio para causar reflexão das ondas de calor e a mesma foi fechada com tampa de vidro transparente (Figura 2).

Figura 1. Construção do tronco de cone.
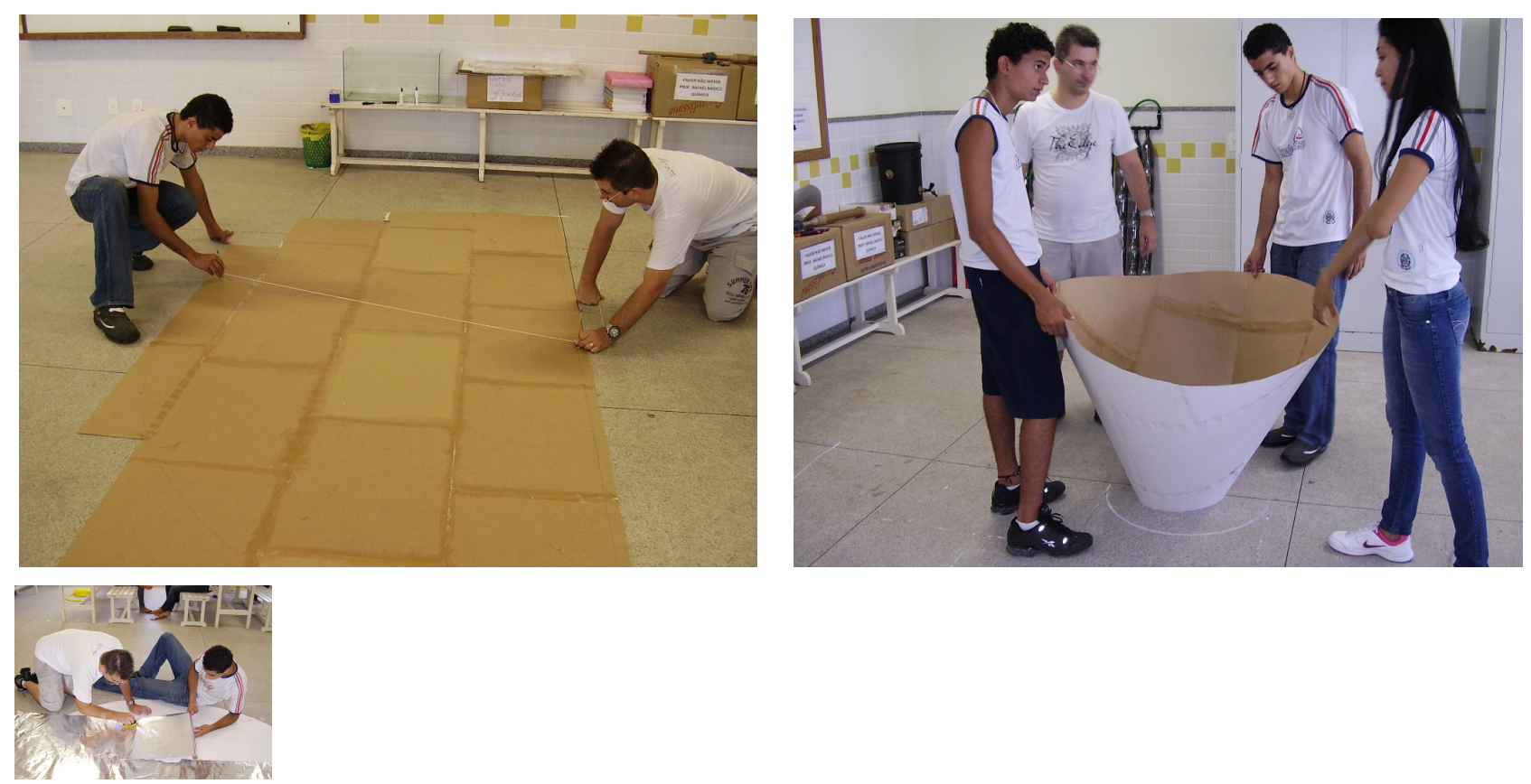

Fonte: Registros da pesquisa. 


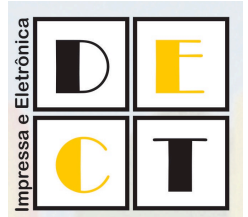

\section{Diversidades e Inclusão Social Atitude sustentável para erradicação da pobreza}

Figura 2. Forno solar em forma de caixa cilíndrica isolada termicamente.
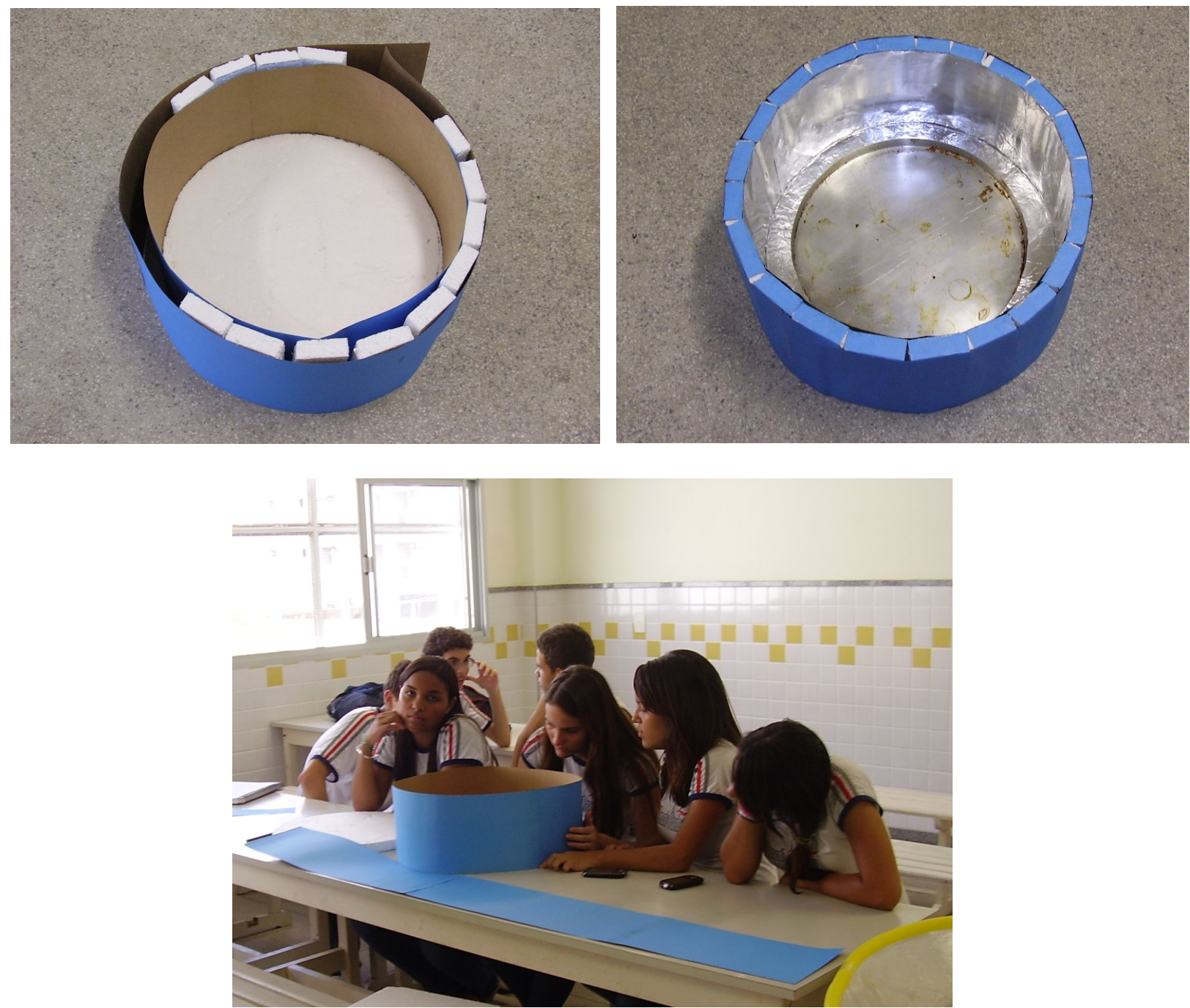

Fonte: Registros da pesquisa.

\section{Confecção dos fornos em configuração de caixa.}

O forno propriamente dito, local onde ocorre o efeito estufa e cozimento dos alimentos, foi confeccionado em forma de paralelepípedo utilizando caixas de papelão isolado termicamente com isopor e revestidas com papel cartão. 0 interior da caixa foi revestido com papel alumínio para causar reflexão das ondas de calor e a mesma foi fechada com tampa de vidro transparente. Para aumentar a concentração de raios solares no interior da caixa, foram acopladas abas revestidas em papel alumínio em posições estratégicas da caixa. 0 projeto empregou conhecimento de trigonometria e posicionamento geográfico (Figura 3). 


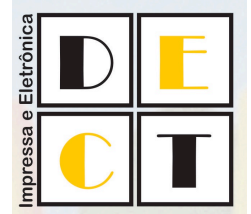

\section{Diversidades e Inclusão Social Atitude sustentável para erradicação da pobreza}

Figura 3. Forno solar em forma de paralelepípedo isolado termicamente.
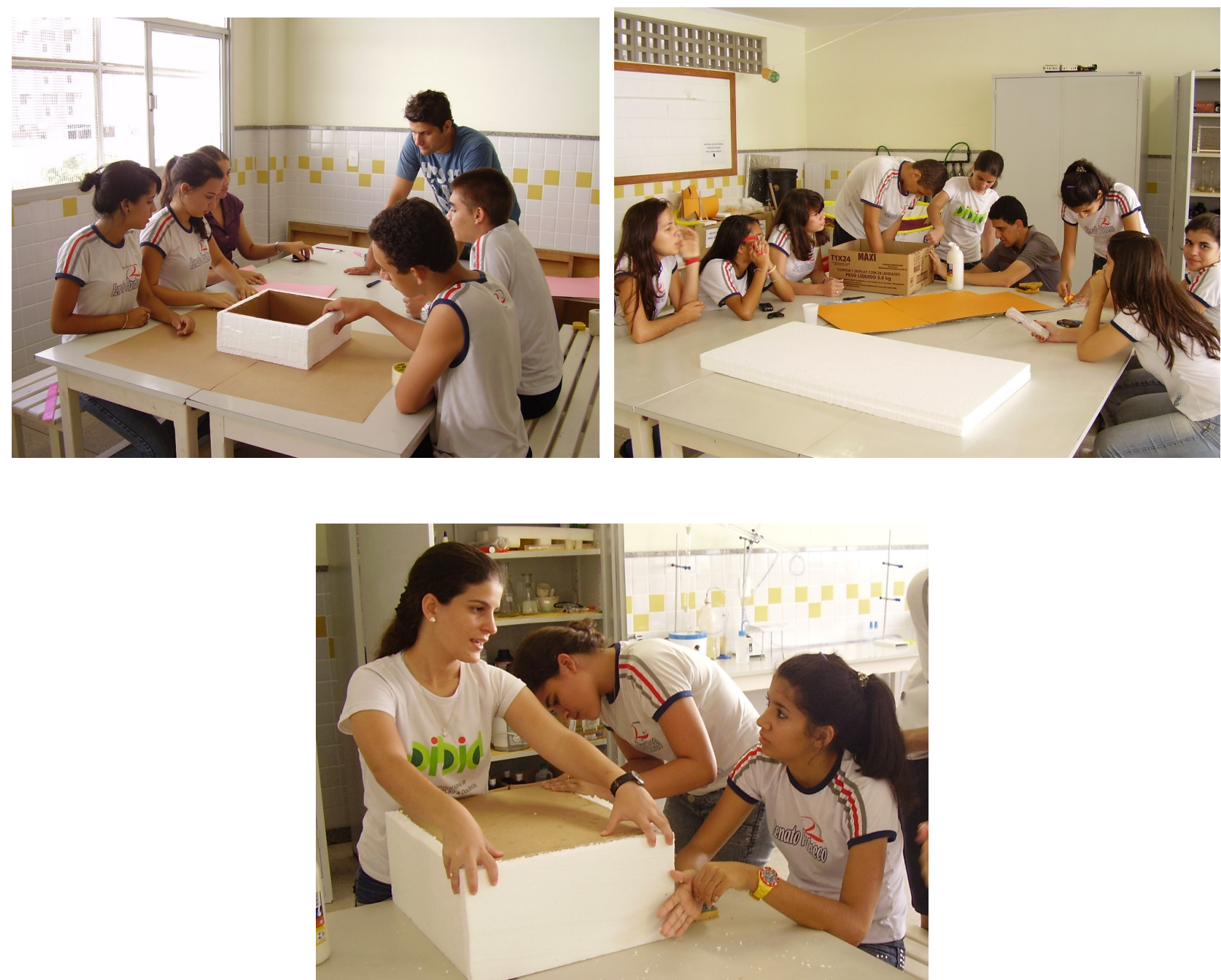

Fonte: Registros da pesquisa.

\section{RESULTADOS E DISCUSSÃO}

Testes realizados no verão mostraram-se satisfatórios e possibilitaram assar bolos, pizzas e pão de queijo (Figura 4), mas no inverno, os resultados esperados não foram alcançados devido a pouca incidência de sol e a nebulosidade, resultando em maior tempo para aquecimento do forno e cozimento incompleto dos alimentos. Os testes também despertaram muita curiosidade da equipe de professores e demais funcionários da escola. 
Figura 4. Projeto finalizado e alimentos assados.
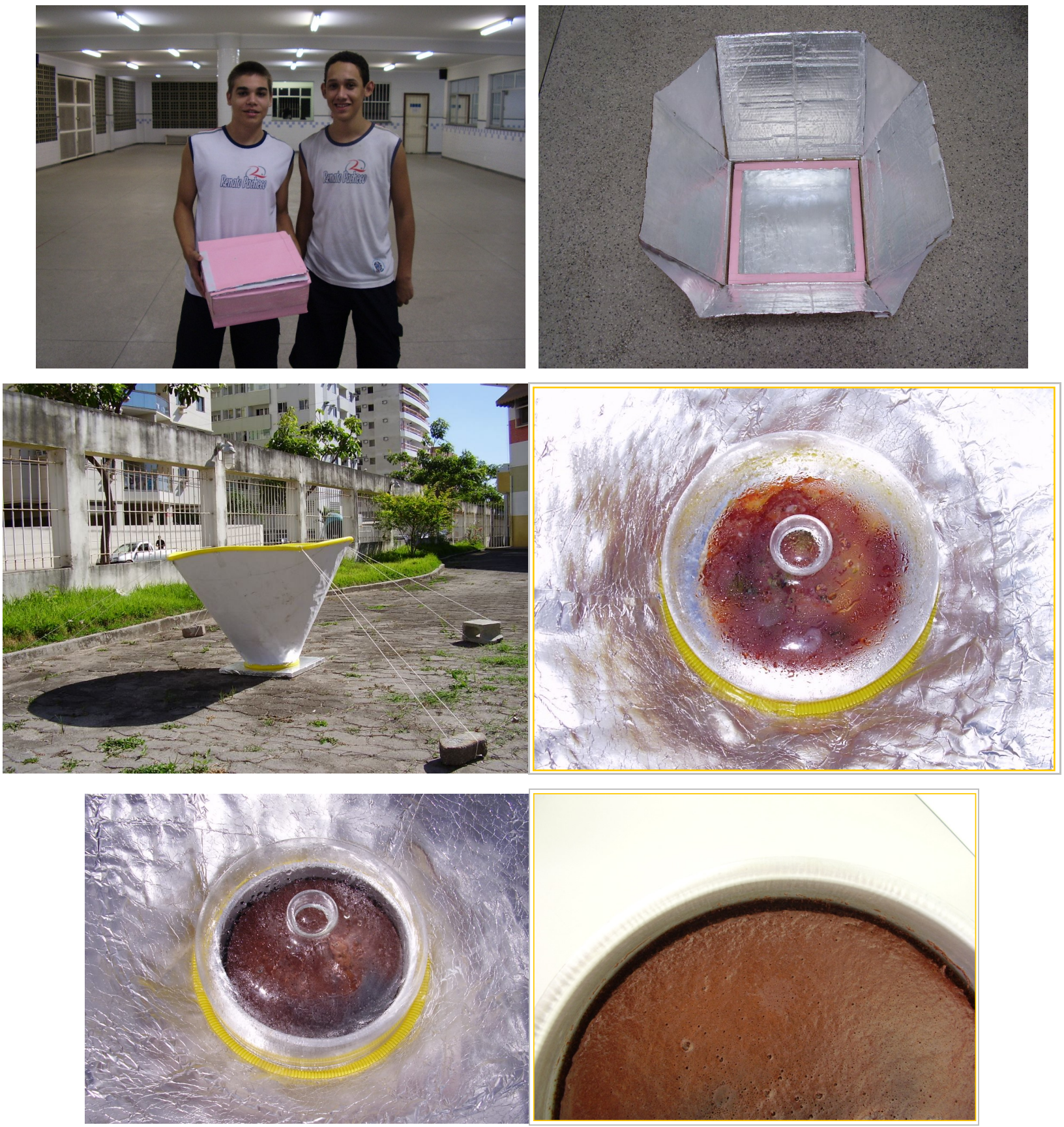

Fonte: Registros da pesquisa.

\section{CONCLUSÃO}

Os resultados dos fornos solares foram satisfatórios, os alunos se empenharam na sua construção e teste, cada um fazendo a tarefa que lhe foi destinada. Os alunos foram levados a 


\section{Diversidades e Inclusão Social

ter uma visão mais crítica sobre a situação ambiental do nosso planeta, refletindo sobre o uso de tecnologias sustentáveis.

Nos relatos acima descritos pode-se perceber quanto o assunto é interdisciplinar, aborda questões de trigonometria, geometria espacial, geografia, química e física, ação que é muito discutida e almejada na educação.

\section{AGRADECIMENTOS}

O presente trabalho foi realizado com apoio do Programa Institucional de Bolsa de Iniciação à Docência - PIBID, da CAPES - Coordenação de Aperfeiçoamento de Pessoal de Nível Superior Brasil.

\section{REFERÊNCIAS}

LOUBACK, Artur. Como funciona? - 0 forno solar. Disponível em: $<$ http://planetasustentavel.abril.com.br/noticia/energia/conteudo_269572.shtml $>$. Acessado em 07 de abril de 2012.

TUDOSOLAR. Forno solar. Disponível em:

$<$ http://www.youtube.com/watch?v=YbWl_ZHKoIU>. Acessado em 07 de abril de 2012.

SOCIEDADE DO SOL. Forno Solar de Baixo Custo. Disponível em: $<$ http://www.sociedadedosol.org.br/fornosolar/fornoss.htm> Acessado em 07 de abril de 2012.

AALFS, Mark. Princípios dos Projetos dos Fogões Solares de Caixa. Disponível em: $<$ http://www.solarcooking.org/portugues/sbcdes-pt.htm> Acessado em 07 de abril de 2012.

Jornal hoje. Fogão a energia solar. Disponível em:

$<\mathrm{http}: / / \mathrm{www}$.youtube.com/watch?v=5vvq1FZ8zHo\&feature=endscreen\&NR=1> Acessado em 17 de julho de 2012 . 